\title{
Automated Course Advising System
}

\author{
Mohammad S. Laghari, Member, IACSIT
}

\begin{abstract}
Student course registration is an important as well as a trivial process that may encounter unnecessary graduation delays. Electrical Engineering Department of the United Arab Emirates University $(U A E U)$ is one such place where students have faced problems such as, a lack of a proper advising system, awareness and experience of advisers, students' ability to seek good advice, inappropriate advising time schedules, etc. Students not advised fittingly may suffer with problems which may include, course selection with time conflicts, missing out on suitable courses for specific semesters, choosing electives bypassing track restrictions, selecting too many or less courses, selecting unnecessary and incorrect courses, etc. An Automated Course Advising System (ACAS) is devised to guide students in selecting appropriate courses suitable to register online with the Banner System. ACAS software is developed by using JAVA computer programming language. The system is easily operated and the outcome of the course selection is stored to show a complete typical plan.
\end{abstract}

Index Terms-Advising, automation, course planning, knowledge engineering, software package.

\section{INTRODUCTION}

The purpose of the registration process at an academic institution is to determine which students will be taking what courses within the university education system as well as for the administration to follow its track and keep its records up-to-date. From the students' point of view, the registration process enables them to acquire the necessary authorized membership of the University and enables them to obtain their legal \& authorized benefits and privileges. Typically, students register for particular courses, and this information helps the administration to construct class lists and offer other academic activities, etc.

The devised system at the College of Engineering helps and guides students in selecting appropriate courses suitable to register with the online University Registration System. Typically, a student needs to consult his/her Academic Adviser before the start of the registration period, this consultation is however, commonly plagued with delays or even a complete miss out with either adviser too busy or the student too lazy to seek an appointment. Although, the registration system ascertains an academic hold on the online course selection but this hold is administratively released on the second day of student registration.

Most of these losing out students experience problems which may include, course registration without completing prerequisites, course selection with time conflicts, miss out on specific courses which may be only offered for alternate

Manuscript received September 5; revised November 14, 2013.

M. S. Laghari is with the Department of Electrical Engineering, UAE University, P. O. Box: 15551, Al Ain, United Arab Emirates (e-mail: mslaghari@uaeu.ac.ae). semesters, selecting department electives bypassing track requirements and restrictions, selection of general education, culture, humanities, and social sciences courses restricted for specific colleges. Selecting too many or too less courses in a specific semester whereas this selection is typically based on academic warnings, minimum credit hour requirements, and/or low grade point averages, etc.

Students in some of these categories may suffer with problems such as, class expulsion after two or three weeks of the start of the semester because of prerequisites requirement, delayed graduation due to additional but unnecessary taken courses, miss out of a complete semester because of the minimum number of courses requirement, etc. The ACAS is devised to counter such student problems of advising and registration. The advising system helps and guide students in selecting precise and appropriate courses suitable for online registration.

The paper describes complete operation of the advising software package, which includes prioritized course selection, course hierarchies, graphical charts, restrictions, complete course plans, etc. Students can run the advising program at any time in their degree career and create a typical course selection plan for the remaining semesters, in the form of a semester wise saved file. Case study of a typical student has been reported and analyzed in this paper.

The system is under test in the department whereas modifications are in progress to suit the department and student needs. Moreover, most of the test trials have resulted in accuracy. Once the testing phase is complete, the advising program will be investigated to implement in all departments of the College of Engineering. Work is also in progress to convert the advising JAVA application program into a JAVA applet. This completed applet will be mounted on the college web server for students to access the advising system online.

\section{ADVISING AND REGISTRATION SYSTEMS}

This section looks at some of the similar old and recent advising systems.

The PACE advising system is a decision model representation for course advising based on student's need to know "what to do" and "how to do it". It consisted of profiling a student's strengths and weakness, generating a personal curriculum customized to each student needs, and producing a schedule for the courses chosen [1].

The advising software at the Electrical Engineering, Texas Tech University featured a graphical user interface, that allowed students to request only courses for which they have appropriate prerequisites, co-requisites, and standing [2]. Similar work has been investigated by authors on an old and phased out curriculum [3].

A Student Advising Software ( $S A S$ ) is developed by using 
JAVA computer programming language. It is a manual procedure, which helps and guides students in selecting appropriate courses suitable for online registration with the Banner University Registration System [4]. An improved version of Student Advising \& Planning Software is developed at the Electrical Engineering Department, UAE University. It is an automated system with limited functionality and about a $20 \%$ error rate [5], [6]. The academics at the Florida Atlantic University developed a similar web-based advising system that supplemented the conventional advising process [7].

A Bayesian Network model for planning course registration and advising by using a data mining technique is developed to predict the sequences of courses to be registered by undergraduate students whose majors are computer science or engineering [8].

A SASSY advising system is developed at the Armstrong Atlantic State University. This system suggests courses for an advisee based on; frequency of the course offering, balancing the course load, shortening the path length to graduation, preference of advisee and entertaining different scenarios of course loads for the entire duration of the advisee's university life [9].

Two project management tools are designed to help the students complete their degree plan sooner. The first tool provides a visualization map of course sequences, customized for each student, making advising adjustments that will optimize the time to obtain the degree under a constrained set of resources. The second tool is to collect information from multiple students through several semesters and is used to identify bottlenecks in the curriculum [10].

An expert system using JESS (a JAVA based rule engine and scripting environment) is developed that allows students to seek quick responses to their queries regarding their plan of study and progress in the program [11].

The Arjuna distributed system was developed at The University of Newcastle upon Tyne, UK. Its design aims were to provide tools to assist in the construction of highly available, fault tolerant distributed applications using atomic actions. Shrivastava et al. have discussed the design and implementation of a registration system that successfully met their requirements [12], [13].

Another development was completed at the Wylie College IT for software architectural development of a course registration system using the specifications created for the college requirements. The Software Architecture Document provides an architectural overview of the C-Registration System. The C-Registration System was initiated by Wylie College IT to support online course registration [14].

As from one advising and registration system to another are browsed, it has been speculated that specification document is fundamental and the key to further developing a customized university course registration. Furthermore, as programs to be offered vary from institution to institution, and at the same time, universities continuously revise their curriculum as well as program requirements in order to meet market demands, the flexibility and reliability of the registration system to accommodate such changes in the program offerings has been deemed necessary for such a system to survive and evolve.

Therefore, the required development work involves customized design of a network-enabled university student registration system that is capable of handling scenarios such as add/drop requests, student advising, availability of courses per term, student's registration status, enrolment summary, reports, etc.

\section{THE ACAS PACKAGE}

The College of Engineering has 1900 students distributed in five departments. Students from Electrical Engineering Department (200 students) take 147 credit hours of course work to fulfill the requirements for a B.Sc. degree in either of the two disciplines of Electrical Engineering or Communications Engineering. An average course load of 15 to 18 credit hours per semester (comprising 4 to 6 courses) is typical to complete their degree requirements in roughly 8 to 9 semesters.

The total number of credit hours of course work is divided into University General Requirements Unit (UGRU) - 21 credits, Engineering Requirements Unit $(E R U)$ - 41 credits, Department Compulsory Specialization Requirements - 52 credits, Department Elective Specialization Requirements 12 credits, Industrial Training - 15 credits (based on a complete semesters load), and the Graduation Projects - 6 credits (distributed in two semesters).

The ACAS package consists of the interface as shown in Fig. 1. The display consists of two text columns, a student information section, several interactive buttons, and a 'Total Credits' information window. The left text column displays all courses of the department. A typical advising session starts with the student pressing the 'Student' button shown in the lower button panel of the package. This allows the user to enter information such as the student name, ID, Grade Point Average (GPA), degree major, and the current date. The 'Select' interactive button, and by using the mouse click on the course list in the left text column, creates another list of all passed and currently registered courses, displayed in the right text column.

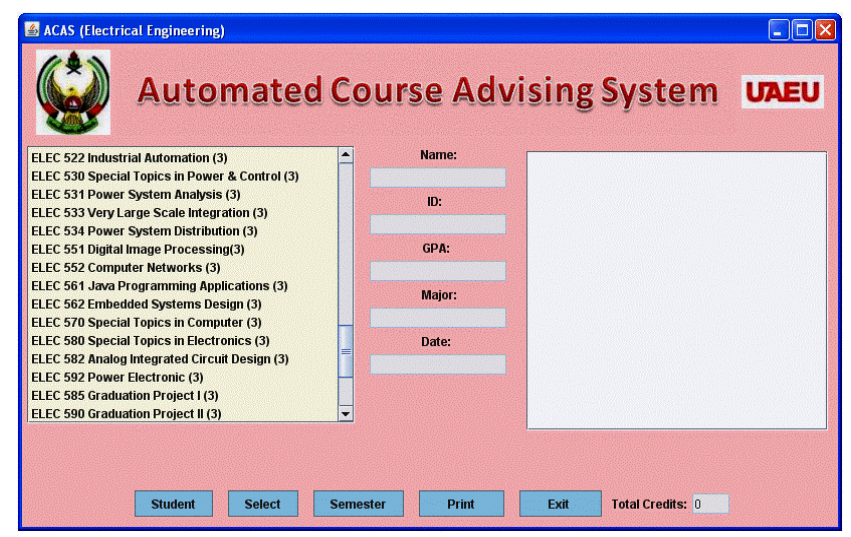

Fig. 1. Interface of ACAS software package.

After this selection procedure, the system is now ready for auto advising mode. The student can start the process of automated course selection by pressing the 'Semester' interactive button. Although, the system is programmed to recognize the student GPA and chooses the semester load accordingly but alternatively it also allows the student to decide on the average credit hours of load per semester.

This semester wise selection procedure continues selecting 
courses for each proceeding semester by continuously pressing the 'Semester' button until all the degree requirement courses are chosen and displayed. The credit hours window is also successively increased to show the completed credits. Subsequently, each next semester courses are displayed in the right displayed column of the package until the final semester to complete 147 credit hours of degree requirement. All succeeding displays are saved in a file for the student to keep a record of advising to use for the registration purpose. The ACAS package is described in detail in the following section in terms of two typical advising plans.

\section{TEST CASE}

The software package automatically calculates the average credit hours/semester as well as the total number of semesters for completion, which is based on student entered course data. For example, if the student has completed 41 credits, then the remaining \# of credit hours is $147-41=106$. The remaining also includes 15 credits for industrial training semester. With a typical student's CGPA of 3.00, an average of 16 credit hours of course work is set by the system, and based on this average the student needs a total of 7 more semesters including industrial training.

Alternatively, a student is given a choice to calculate for a slow, normal, or a fast track of degree completion. More than six courses per semester may be chosen for a fast track degree. Fig. 2 shows the pop-up window asking for student's choice of the semester average credit hours load. As compared to the above-mentioned example, an appropriate selection of 16 credit hours suits the student GPA, which by average wise is not far from the systems choice but equivalent to the total number of semesters. A less credits/semester of 14 would delay the degree and more would be one less semester but definitely a work burden on the student.

\begin{tabular}{|c|c|}
\hline Gourses Plan Duration & $=\square \times$ \\
\hline \# of Semest & ers Needed \\
\hline Average CH/Semester & \# of Semesters \\
\hline$\square 14$ credit hours each: & 8 semesters \\
\hline$\nabla 16$ credit hours each: & 7 semesters \\
\hline$\square 18$ credit hours each: & 6 semesters \\
\hline Select & Exit \\
\hline
\end{tabular}

Fig. 2. Choice of average credit hours loads per semester.

In an advising session, a student inputs all previously passed or currently registered courses. The system is then programmed to find the next advising semester to be either first or second. This selection, which is based on the entry date of student's information phase, always selects the next advising semester of either first starting in September or second that starts in February.

The system displays not all but only specific courses for the next advising semester whose prerequisite has already been passed by the student. For example, if a student has passed 21 odd courses then only a shorter list of courses is considered by the system to display. Therefore, the systems' decision to display specific courses is not based on all courses offered in the semester but on a shorter list.

The ACAS decision to choose a specific course from a pool of offered and appropriate courses is based on the knowledge area built around each course. Fig. 3 shows the ELEC $305-$ Electric Circuits I course with its associated knowledge area.

All courses are grouped together with five additional fields. The value 2 associated in the $1^{\text {st }}$ field indicates that the course has two forward hierarchical levels. The $2^{\text {nd }}$ field indicates the number (2) of course(s) to open in the next semester, which is dependent on this particular course. The $3^{\text {rd }}$ indicates that there are seven courses in the following semesters dependent on this course. The $4^{\text {th }}$ field indicates the number of department electives dependent on this course, and the last field value of ' 1 ' indicates that this course is required for industrial training.

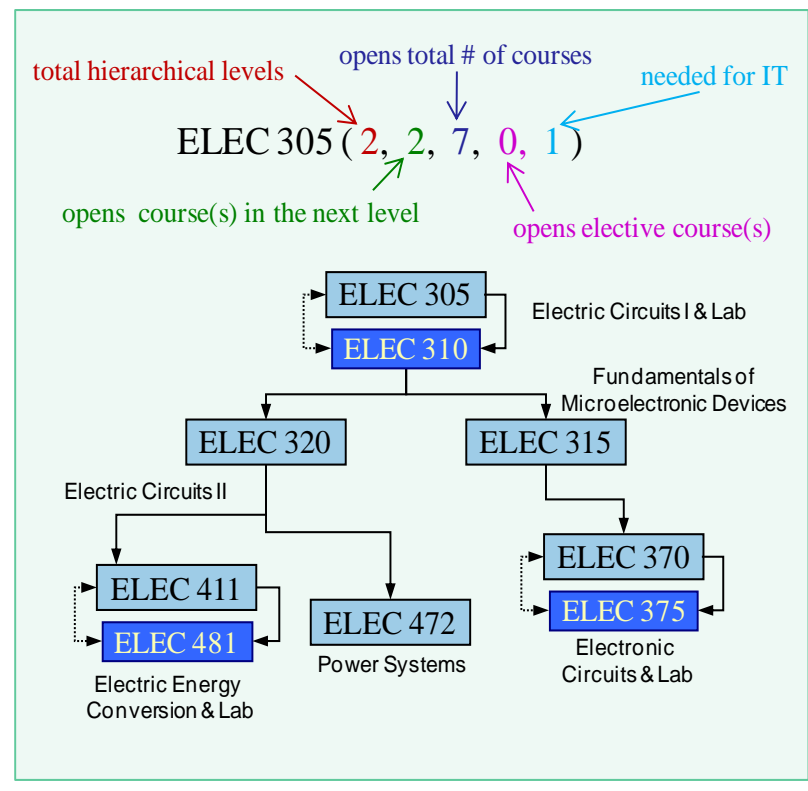

Fig. 3. Systems' knowledge area with associated fields.

The associated course fields are prioritized in the auto advising system with the first field having the highest priority. The advising selection procedure performs a field wise comparison of all suitable short listed courses. Courses with a higher first field value are chosen first. If there are courses remaining to fit in a semester and the first field value is same for many such courses then second field priority is considered. Again, the second level of selection is the choice of which course opens more courses of the next semester. If still more courses for a specific semester is required then the third field is considered. Fourth field is considered a higher priority than the last one meaning that opening of number of electives is more important than the courses considered for industrial training. Finally, courses with a ' 1 ' in the last priority field are important for considering industrial training.

There is also a chance that there may be two or more courses with same field choice being considered for a specific semester. The student is then allowed to choose between the courses of interest.

\section{A. Course Plan with 16 Credit Hour Average}

A course plan shown here is based on Fig. 2 and Fig. 3, respectively. Fig. 4 shows a complete plan of the above-mentioned example displaying all eligible courses and their associated selections (ticks) for seven semesters as 
reflected by the ACAS package.

Analyzing courses for the Spring 2012 semester shows that instead of 21 plus courses only 12 are considered based on the prerequisite information. From these six courses are selected again based on the field priorities and the credit hours approaching the set average. PHYS 1120 could have been considered but then the total number of semester credits would zone out of the average.

Fall 2012 semester selects courses equaling 17 credit hours. Although heavier but the selection is based on the balanced load on the remaining semesters and more importantly selecting courses based on the prioritized first three fields.

Spring 2013 semester prefer course selections more on opening elective courses in the following semesters rather than choosing courses suitable for industrial training.

Fall 2013 semester selects all courses suitable for industrial training as well as any other course, which opens more elective choices. The system understands that this is the last semester before training as the total is equivalent to prerequisite for training. Although electives are considered, priority to select an elective before training is lower than any other compulsory course.

Spring 2014 semester is the industrial training semester, which is based on the total number of credit hours before training.

Fall 2014 and Spring 2015 semesters need to select at least two of the four department electives each semester.

Similar to selection for the compulsory courses, department electives are also separated to offer in two semesters. In following the advising phase, when department electives become a priority, the system automatically displays an electives list specific for the offering semester. The student is then given a choice to select an appropriate elective(s) of interest.

Both of the semesters offer a separate set of departmental electives. However, at the course offering time for a scheduled semester the chances are that the earlier chosen electives may not be offered because all semester electives are not offered at all times. Therefore most definitely, the student has to choose another department elective being offered at that specific registration time. Alternatively, the student may request a particular elective to be offered.

All engineering students take four general education, culture, humanities, \& social science courses, which are offered by other colleges. Similar to the department electives not all of the university courses are offered in both semesters. Therefore, the system automatically selects courses with generic names. At the time of registration, student chooses courses of interest from a pool of university offered courses.

\section{B. Alternate Course Plan with 18 Credit Hour Average}

If the student in the previous example decides to save a semester and chooses the 18 credit hours of average course work per semester then Fig. 5 shows an alternate complete plan displaying all eligible courses and their associated selections (ticks) for six semesters as reflected by the ACAS package. Although, saving a semester seems attractive but the final two semesters would end up with heavy workloads and most probably may influence student's cumulative grade point averages.

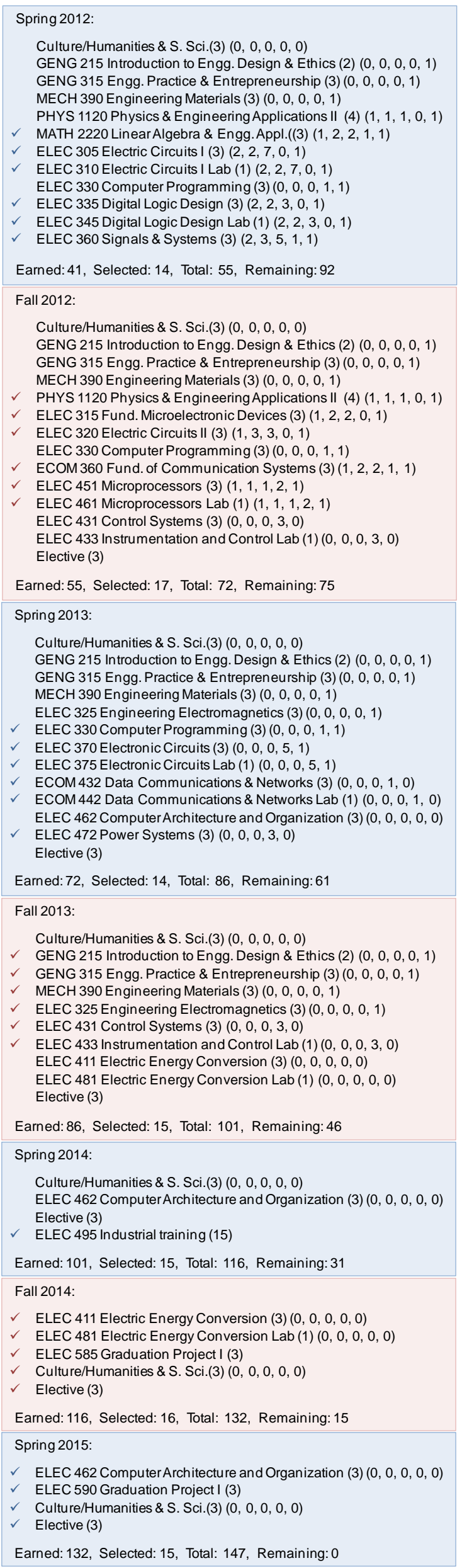

Fig. 4. A complete course plan consisting of 7 semesters. 


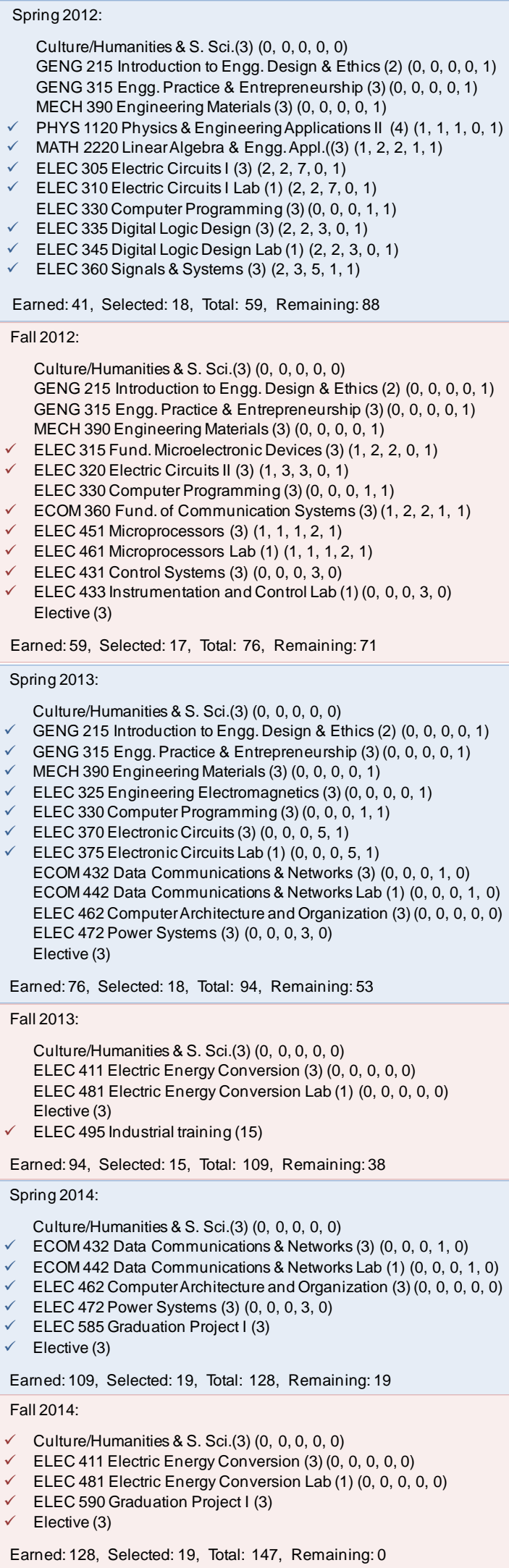

Fig. 5. A complete course plan consisting of 6 semesters.

\section{CONCLUSION}

Student course registration is an important as well as a trivial process, which may encounter unnecessary graduation delays. An Automated Course Advising System has been devised to guide students in selecting appropriate courses suitable to online registration. The outcome of the course selection is stored (semester wise) to show a complete typical plan. Future work will concentrate on integrating the automatic procedure with a manual procedure investigated earlier.

\section{REFERENCES}

[1] H. Gunadhi, K. Lim, and W. Yeong, "PACE: a planning advisor on curriculum and enrollment," in Proc. 28th Annu. Hawaii Int. Conf. System Sciences, Maui, Hawaii, 1995, pp. 23-31.

[2] M. Hagler, "A stand-alone pc-based advising aid for students," in Proc. Frontiers In Education Conf., Atlanta, Georgia, 1995, pp. 3a3.18-3a3.21

[3] M. S. Laghari, Q. A. Memon, and H. Rehman, "Advising for course registration: a uae university perspective," in Proc. Int. Conf. on Engineering Education (ICEE), Gliwice, Poland, 2005.

[4] M. S. Laghari and G. A. Khuwaja, "Electrical engineering department advising for course planning," in Proc. IEEE Global Engineering Conf. - EDUCON2012, Marrakech, Morocco, 2012, pp. 861-866.

[5] M. S. Laghari and G. A. Khuwaja, "Course advising \& planning for electrical engineering department," Journal of Education and Instructional Studies in the World, vol. 2, no. 2, pp. 172-181, 2012.

[6] M. S. Laghari and G. A. Khuwaja, "Student advising \& planning software," Int. Journal on New Trends in Education and Their Implications, vol. 3, no. 3, pp. 158-175, 2012.

[7] O. Marques, X. Ding, and S. Hsu, "Design and development of a web-based academic advising system," in Proc. $31^{\text {st }}$ ASEE/IEEE Frontiers in Education, Reno, Nevada, 2001, pp. S3C-6-S3C-10.

[8] P. Pumpuang, A. Srivihok, P. Praneetpolgrang and S. Numprasertchai, "Using bayesian network for planning course registration model for undergraduate students," in Proc. $2^{\text {nd }}$ IEEE Int. Conf. on Digital Ecosystems and Technologies, Phitsanulok, Thailand, 2008, pp. 492-496.

[9] R. R. Hashemi and J. Blondin, "SASSY: a petri net based student-driven advising support system," in Proc. 7th Int. Conf. on Information Technology, Las Vegas, Nevada, 2010, pp. 150-155.

[10] V. Gonzalez and D. Esparza, "Work in progress - advising tool to improve the time for graduation and the transfer of students from a community college to engineering school," in Proc. $40^{\text {th }}$ ASEE/IEEE Frontiers in Education, Washington, DC, 2010, pp. T3H-1-T3H-2.

[11] A. N. Nambiar and A. K. Dutta, "Expert system for student advising using JESS," in Proc. Int. Conf. on Educational and Information Technology, San Francisco, 2010, pp. V1-312-V1-315.

[12] S. K. Shrivastava, G. N. Dixon, and G. D. Parrington, "An overview of arjuna: a programming system for reliable distributed computing," IEEE Software, vol. 8, pp. 63-73, 1991.

[13] F. Panzieri and S. K. Shrivastava, "Rajdoot: a remote procedure call mechanism supporting orphan detection and killing," IEEE Trans. on Software Engineering, vol. 14, no. 1, pp. 30-37, 1988.

[14] G. D. Parrington et al., "The design and implementation of arjuna," USENIX Computing Systems Journal, vol. 8, pp. 253-306, 1995.

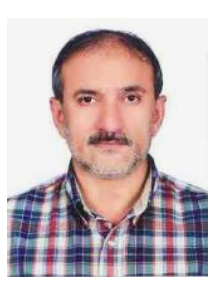

Mohammad S. Laghari received his B.E. degree in electronic engineering from Mehran University of Engineering and Technology, Pakistan, M.S. degree in electrical engineering from Drexel University, Philadelphia, USA, and $\mathrm{Ph} . \mathrm{D}$. in computer engineering from the University of Wales, UK in 1980, 1983, and 1993, respectively.

He has taught at the Kuwait University, King Saud University and is currently an associate professor in the Electrical Engineering Department, United Arab Emirates University, U.A.E. His research interests are in applied artificial intelligence, image processing, pattern recognition, and software systems. He has published more than 65 papers in these areas.

Dr. Laghari is a member of the IACSIT (Singapore), PEC (Pakistan), UACEE (USA), and IRED (USA). 